\title{
Bullying: Conhecimentos, Atitudes e Crenças de Professores
}

\author{
Jorge Luiz da Silva \\ Wanderlei Abadio de Oliveira \\ Marina Rezende Bazon \\ Universidade de São Paulo \\ SP, São Paulo, Brasil \\ Sálua Cecilio \\ Universidade de Uberaba \\ Uberaba, MG, Brasil
}

\begin{abstract}
RESUMO
O presente estudo investigou se professores de $6^{\circ}$ ano do Ensino Fundamental conheciam, identificavam e como intervinham nas situações de bullying ocorridas em sala de aula. Participaram seis professores e os dados foram obtidos por meio da técnica de grupo focal, em 2010. Utilizou-se a análise de conteúdo no tratamento do material coletado. Dentre os resultados, obteve-se que os professores não possuíam conhecimentos suficientes acerca das principais características deste fenômeno, bem como a respeito de sua gravidade, indicando realizarem intervenções, em sua maioria, pontuais, circunscritas aos eventos identificados e após a ocorrência desses. Também referiram sentirem-se insuficientemente preparados para identificarem e lidarem com as agressões praticadas pelos alunos. Assim sendo, depreende-se que a formação dos professores constitui um aspecto importante a ser trabalhado em programas de prevenção e intervenção sobre o bullying escolar.
\end{abstract}

Palavras-chave: Bullying; violência escolar; interação professor-aluno; agressividade; adolescência.

\section{ABSTRACT}

\section{Bullying: Teachers'Knowledge, Attitudes and Beliefs}

This study's objective was to investigate whether 6th grade teachers knew, identified and how they intervened in bullying situations occurring in classrooms. Participants were six teachers and the data were obtained through the focus group technique in 2010. Content analysis was used to treat the collected material. The results revealed that the teachers did not have sufficient knowledge concerning the main characteristics of this phenomenon, nor realized how serious it is. Their interventions were mostly occasional and limited to the events they identified and after their occurrence. The teachers reported not being sufficiently prepared to identify and deal with students' aggressive behavior. Hence, we infer that teacher training is an important aspect that should be addressed in bullying prevention and intervention programs.

Keywords: Bullying; school violence; interaction teacher-student; aggressiveness; adolescence.

\section{RESUMEN}

\section{Acoso: Conocimientos, Actitudes y Creencias de Profesores}

En este estudio fue investigado se profesores del $6^{\circ}$ año de la Educación Primaria conocían, identificaban y como intervenían en las situaciones de bullying ocurridas en la clase. Los participantes fueron seis profesores y los datos fueron obtenidos a través de la técnica de grupo focal en el 2010. Se utilizó el análisis de contenido en el tratamiento del material colectado. Entre los resultados, se encontró que los profesores no poseían conocimientos suficientes acerca de las principales características de este fenómeno, ni respecto a su gravedad, indicando que la mayoría de las intervenciones realizadas fueron circunscritas a los eventos identificados y tras su ocurrencia. También refirieron que se sienten insuficientemente preparados para identificar y lidiar con las agresiones practicadas por los alumnos. Así, se infiere que la formación de los profesores representa un aspecto importante a ser trabajado en programas de prevención e intervención sobre el bullying escolar.

Palabras clave: Bullying; violencia escolar; interacción profesor-alumno; agresión; adolescencia. 


\section{INTRODUÇÃO}

O bullying, um tipo de violência interpessoal, é considerado um problema importante a ser investigado e combatido nas escolas (Boulton et al., 2012). Em termos de definição, constitui qualquer comportamento ou atitude agressiva intencional, repetitiva e realizada dentro de uma relação desigual, em termos de poder, entre vítimas e agressores. As agressões praticadas são múltiplas e variadas, abrangendo desde ataques físicos e verbais, denominados bullying direto, até comportamentos mais sutis e secretos, classificados como bullying indireto, tais como, por exemplo, espalhar boatos, fazer fofocas ou isolar a vítima do grupo de pares na intenção de prejudicar a sua posição social (Olweus, 2013; Pingoelo \& Horiguela, 2010; Salmivalli \& Voeten, 2004; Smith, Smith, Osborn, \& Samara, 2008).

O bullying ocorre em contextos interacionais dinâmicos nos quais os sujeitos desempenham papéis específicos: agressores, vítimas ou espectadores. Cada um desses papéis se subdivide em perfis, segundo as características que os tipificam (Ahtola, Haataja, Kärnä, Poskiparta, \& Salmivalli, 2012; Olweus, 2013; Wendt, Campos, \& Lisboa, 2010). Tal estratificação evidencia a complexidade desta problemática, denotando a necessidade de melhor domínio teórico e conceitual para a sua definição, caracterização e formas de manejo pela equipe escolar, com vistas a prevenir, controlar e combater sua manifestação nas escolas.

Destaca-se que o conhecimento acerca do bullying tem avançado sistematicamente, tendo por base a produção científica em torno do tema, que cresceu enormemente nas últimas décadas, associada à expansão das vertentes teóricas empregadas para a abordagem deste fenômeno, o que tem possibilitado sua caracterização de modo cada vez mais global e aprofundado. Isto tem favorecido sua interpretação para além do ponto de vista estrito da interação entre agressor e vítima, permitindo, por exemplo, reconhecer o papel desempenhado pelos espectadores na produção desta problemática, uma vez que, apesar de nem sempre participarem diretamente das agressões, a simples presença desses, enquanto plateia ou como incentivadores, reforça a conduta dos agressores, além deles mesmos serem afetados negativamente pela violência que presenciam. Investigações recentes também têm considerado a inserção do bullying no contexto das grandes instituições de socialização dos sujeitos, tais como, a família, a escola e o grupo de pares, identificando as influências diretas e indiretas exercidas por estas instituições sobre os comportamentos violentos dos alunos (Ahtola et al., 2012; Boulton et al.,
2012; Hernandez, Floden, \& Bosworth, 2012; Janosz et al., 2008; Silva, Pereira, Mendonca, Nunes, \& Oliveira, 2013; Smith et al., 2008).

As consequências do bullying incidem sobre todos os sujeitos envolvidos nas suas práticas, podendo ser associadas à manifestação de diversos desajustes psicossociais. Para as vítimas e espectadores, decorrem das agressões, sofridas ou presenciadas, sensação de medo, insegurança, ansiedade, retraimento, dificuldade de concentração, diminuição da autoestima, sentimentos negativistas, depressão e, em casos mais graves, suicídio. Os agressores, em seu turno, podem se envolver em situações de violência doméstica e prática de atos infracionais (Fung, 2012; Hansen, Steenberg, Palic, \& Elklit, 2012; Lisboa, Braga, \& Ebert, 2009; Salmivalli \& Voeten, 2004; Thornberg, Thornberg, Alamaa, \& Daud, 2014; Zaine, Reis, \& Pandovani, 2010). Essas consequências persistem ao longo da vida dos sujeitos, generalizando-se a outros relacionamentos, de modo a exercerem interferência negativa contínua no tocante à vinculação com as pessoas e no funcionamento social em geral.

Compreende-se que um ambiente escolar seguro constitui um requisito básico para a boa aprendizagem e também para o desenvolvimento psicossocial saudável (Ahtola et al., 2012). No entanto, as escolas se distinguem muito na capacidade de proporcionarem segurança nas interações entre os alunos, o que varia também de acordo com as diferentes realidades socioculturais em que estão localizadas. Estudos realizados em outros países, nas décadas de 1980 e 1990, apontavam para índices de vitimização entre 8\% e 38\% e entre $5 \%$ e $9 \%$ para agressão (Sampson, 2009). Na Finlândia, a ocorrência de bullying era de 11,3\% no final da década de 1990 (Kumpulainen et al., 1998), ao passo que na Irlanda era de 49,8\% no início da década de 2000 (O’Moore \& Kirkham, 2001). Outra pesquisa registrou uma média geral de aproximadamente 40\% em 28 países (Due et al., 2005), mesmo índice identificado na cidade do Rio de Janeiro no ano de 2002 (ABRAPIA, 2002). Mais recentemente, em Londres, um estudo identificou uma incidência menor, de 9,1\% (Rothon, Head, Klineberg, \& Stansfeld, 2011), enquanto outro, na Grécia, descreveu um percentual de envolvimento em comportamentos de bullying de 26,4\% (Magklara et al., 2012). No Brasil, a proporção identificada em uma pesquisa nacional foi de $30,8 \%$ (Malta et al., 2010).

As suas altas taxas de ocorrência se relacionam aos seus picos de vulnerabilidade, normalmente localizados nos períodos de transição inerentes ao sistema educacional (Olweus, 2013). Na realidade brasileira, esses períodos correspondem às mudanças de ciclo, 
do $5^{\circ}$ ao $6^{\circ}$ ano, no Ensino Fundamental, e do $9^{\circ}$ ano do Fundamental ao $1^{\mathrm{O}}$ ano do Ensino Médio (Fisher, 2010). No que tange especificamente à transição para o $6^{\circ}$ ano, nota-se a ocorrência de mudanças significativas na estrutura escolar, no controle disciplinar e nas expectativas de rendimento dos alunos. Os contextos escolares ficam maiores, mais impessoais e passam a demandar maior nível de autonomia e autocontrole comportamental norteado por regras, devido à diminuição da intensidade de supervisão direta pela equipe de funcionários. As avaliações também começam a destacar mais o desempenho nas provas do que o esforço pessoal dos alunos (Carroll et al., 2009). Coincide com esse momento, ainda, o início da adolescência, o qual atrela-se a muitas mudanças no desenvolvimento como, por exemplo, o aumento da busca por autonomia em relação aos adultos, o que potencializa as chances de influência por pares. Assim, corre-se o risco do aumento da vulnerabilidade dos adolescentes às situações de violência, especialmente ao bullying, cujas manifestações tornam-se mais verbais e indiretas na adolescência, dificultando sua identificação pelas autoridades escolares (Hernandez et al., 2012).

Os estudos nacionais indicam ser a sala de aula um dos locais da escola em que as práticas de bullying são mais passíveis de ocorrerem (Fisher, 2010; Rech, Halpern, Tedesco, \& Santos, 2013). Em tal contexto, os professores desempenham um papel fundamental na gestão e na prevenção de conflitos entre os alunos. Não obstante, nem sempre identificam as situações mais sutis do fenômeno ou, quando percebem essas e outras ocorrências do problema, decidem não intervir, algumas vezes por considerarem serem eventos típicos da fase etária (Troop-Gordon \& Ladd, 2013). Deste modo, muitos agressores não são responsabilizados pelos atos que praticam; o que acaba reforçando seus comportamentos e aumentando os índices de intimidação, de forma cíclica.

Ademais, investigações apontam que os professores, em geral, tendem a superestimar suas habilidades na identificação do bullying, bem como a eficácia das intervenções que realizam, embora dados indiquem que, em geral, eles relatam a ocorrência de um número significativamente menor de situações, em comparação ao que relatam os alunos (Hektner \& Swenson, 2012). Tal discrepância talvez deva-se à fragmentação do ensino em disciplinas, a partir do $6^{\circ}$ ano, quando cada professor passa a ter poucos momentos de contato com as turmas durante a semana.

No que se refere às intervenções dos professores, essas influenciam o comportamento dos alunos; porém, sabe-se que eles não se sentem suficientemente preparados para agirem de acordo com as especificidades do bullying. Consideram que os conhecimentos que possuem são, muitas vezes, incompletos, o que dificulta o reconhecimento de características essenciais do fenômeno. De igual modo, em determinadas ocasiões, não se reconhecem enquanto possuidores das competências necessárias para intervirem eficazmente (Allen, 2010; Ahtola et al., 2012; Dake, Price, Telljohann, \& Funk, 2003). Importa salientar que, diante da complexidade das relações interpessoais estabelecidas em sala de aula, os professores também podem participar ativamente da prática de intimidação, enquanto agressores ou vítimas. Portanto, torna-se fundamental que estejam bem (in)formados e que se sintam confiantes em relação à sua capacidade de resposta aos incidentes ocorridos na sala de aula, bem como para preveni-los, pois, do contrário, pode prevalecer a tendência deles também se imporem pela violência, serem intimidados ou permitirem que os próprios alunos resolvam os conflitos entre si, sem a sua intervenção (Boulton et al., 2012; Fung, 2012).

Em outra realidade sociocultural (Estados Unidos), estudiosos já se prontificaram a pesquisar o modo como os professores identificam o bullying, quais estratégias de intervenção utilizam, bem como se aspectos pessoais ou do contexto escolar interferem nesse processo de reconhecimento e de intervenção. Ao investigarem se os sentimentos de empatia em relação aos alunos intimidados exerciam algum impacto sobre a gestão do bullying, em sala de aula, Yoon e Kerber (2003) identificaram que os professores eram mais propensos a intervir nas situações que consideravam mais graves ou vexatórias, tais como ataques físicos e verbais, por demonstrarem maior empatia com os alunos envolvidos nestes tipos de agressão.

Troop-Gordon e Ladd (2013), num estudo sobre crenças acerca do bullying e da vitimização, apontaram que os conhecimentos dos professores, bem como as suas crenças, norteavam suas estratégias de resposta ao bullying. Os autores identificaram a existência de três crenças gerais: 1) os alunos não seriam intimidados se se defendessem das agressões; 2) os alunos não seriam intimidados se evitassem o contato com os agressores; 3) o bullying constitui um comportamento normativo que ajuda na aprendizagem das normas sociais. Nas intervenções realizadas pelos professores investigados, a primeira crença encontrava-se associada ao comportamento de dizer aos alunos para resolverem seus problemas por conta própria e às vítimas para se defenderem das agressões. A segunda crença impelia-os a aconselharem os alunos a se esquivarem dos agressores, de modo a evitarem o contato com eles. Já a terceira, ao considerar o bullying um comportamento 
típico, concorria para que se concebesse a necessidade de intervenção como dispensável.

Nos dois estudos denota-se o fato de os professores não terem plena consciência de quanto o bullying afeta os alunos, pois reconhecem apenas parcialmente a sua extensão e gravidade. Ao considerá-lo apenas pela via de sua manifestação física ou verbal, ou enquanto comportamentos normativos, não intervêm ou sugerem às vítimas a autodefesa frente à intimidação sofrida. Com isso, isentam-se da responsabilidade de desenvolverem atuações adequadas, que realmente engendrem mudanças positivas no contexto da violência escolar (Boulton et al., 2012).

Existem indicações de que os alunos que possuem um bom relacionamento com seus professores e que acreditam na sua capacidade de intervenção na resolução de problemas sentem-se mais seguros na escola, apesar da presença de agressores (Ahtola et al., 2012). Entretanto, pouca pesquisa sobre como efetivamente os professores identificam e lidam com o bullying em sala de aula foram implementadas (Roth, Kanat-Maymon, \& Bibi, 2011), especialmente na realidade nacional. Diante desse quadro, considerando a relevância social e científica da problemática, desenvolveu-se o estudo aqui relatado, cujos objetivos foram o de verificar o que sabem/conhecem professores de $6^{\circ}$ ano de uma escola pública de Ensino Fundamental, a respeito de bullying, descrever e analisar suas percepções e crenças acerca do fenômeno, bem como as condições e formas que assumem as intervenções por eles empreendidas.

\section{MÉTODO}

\section{Local}

O presente estudo constituiu uma pesquisa qualitativa de natureza exploratória, desenvolvida no ano de 2010 em uma escola localizada em uma cidade de porte médio do estado de Minas Gerais. À época da realização da pesquisa, a escola atendia aproximadamente 1200 alunos, distribuídos em três turnos. Sua equipe era formada por 45 professores, nove funcionários administrativos, três pedagogas, duas vice-diretoras e uma diretora.

O bairro no qual a escola se localiza é habitado por famílias de baixo status socioeconômico, compostas, em sua maioria, por migrantes das regiões norte e nordeste do Brasil, o que contribui para que assuma características específicas que o distingue dos demais bairros da cidade. As diferenças culturais entre os habitantes, especialmente, oportunizam a instauração de muitos conflitos entre os moradores, conflitos estes que igualmente adentram na instituição escolar.

\section{Participantes}

Participaram da pesquisa seis professores que lecionavam no $6^{-}$ano do Ensino Fundamental da referida escola, sendo quatro deles do sexo feminino. A média de idade encontrada foi de 40,5 anos e a de tempo de atuação no ensino foi de 10,8 anos. Em relação à formação inicial, esses possuíam os seguintes cursos: Biologia, Filosofia, História, Letras e Matemática, tendo o curso de Letras duas ocorrências. Observou-se que todos os participantes possuíam curso de pósgraduação lato sensu e jornada de trabalho dupla ou tripla em escolas públicas.

\section{Instrumentos}

A técnica empregada para a coleta de dados foi a do Grupo Focal, que constitui um "conjunto de pessoas selecionadas e reunidas por pesquisadores para discutir e comentar um tema, que é objeto de pesquisa, a partir de sua experiência pessoal" (Powell \& Single, 1996, p. 449). Embora seja de rápida execução, seu processo possibilita a obtenção de uma grande riqueza de informações qualitativas acerca da problemática investigada em termos de conhecimentos, percepções, conceitos, crenças e condutas das pessoas investigadas. Além de oportunizar insights, uma vez que, "os participantes se dão conta das crenças e atitudes que estão presentes em seus comportamentos e nos dos outros, do que pensam e aprenderam com as situações da vida, através da troca de experiências e opiniões" (Antoni et al., 2001). Mais do que uma técnica de coleta de informações, o Grupo Focal apresenta um potencial formativo, enquanto propicia aos participantes oportunidade de falar, discutir e refletir sobre uma experiência comum e que os afeta. Nesse sentido, a técnica ao permitir a interação e o debate pode facilitar também a busca de alternativa para o que é problema comum dos envolvidos, assegurando a possibilidade de aquisição de novos conhecimentos e redefiniçao de crenças e atitudes.

Como o cerne desta técnica reside na interação estabelecida entre os participantes, o facilitador da discussão precisa assegurar sua efetivação, facilitando-a, de modo a não conduzi-la como uma entrevista grupal (Minayo, 2010). Para a operacionalização do Grupo Focal alguns requisitos precisam ser observados, tais como, por exemplo, a seleção de poucos indivíduos (de seis a dez no máximo), possuidores de características que permitam seu reconhecimento como coletividade e a definição de um roteiro, que pode ser temático aberto ou estruturado (Pires, 2011). Neste estudo utilizou-se um roteiro estruturado, cujas questões norteadoras foram organizadas em três blocos: 1) conhecimento 
e crenças dos professores sobre bullying; 2) formas de identificação da violência durante as aulas e sua distinção de outros comportamentos como a indisciplina, por exemplo; 3) comportamentos adotados diante da identificação de situações de bullying entre os alunos.

Destaca-se que realizou-se três encontros para a implementação do Grupo Focal. Nesses, além das questões previamente elaboradas, outras foram sendo acrescentadas no decorrer dos encontros, em conformidade ao formato e direcionamentos assumidos pela argumentação dos participantes na interação coletiva do grupo. Também foram utilizados dois disparadores para as discussões, sendo eles uma imagem e um vídeo curto (Boggio \& Pavão, 2005) de aproximadamente cinco minutos, ambos insinuando situações de bullying na sala de aula. O objetivo dos disparadores foi o de verificar se os professores conseguiriam identificar nos cenários hipotéticos as situações de intimidação presentes nas interações entre os personagens, de modo complementar aos relatos sobre situações cotidianas reais por eles vivenciadas.

\section{Procedimentos de coleta e análise de dados}

A coleta dos dados teve início após a aprovação da pesquisa pela Secretaria Municipal de Educação, direção da escola e Comitê de Ética em Pesquisa da Universidade de Uberaba (protocolo CAAE no 0011.0.227.000-10 e parecer 031-2010). Os 12 professores das quatro turmas de $6^{\mathrm{O}}$ ano da escola investigada foram convidados a participar do estudo, considerando que, como individualmente passam pouco tempo semanal com cada turma, a participação de todos poderia oferecer panorama mais detalhado da situação investigada.

De início, todos os professores recusaram-se a participar, por não poderem comparecer aos encontros do Grupo Focal que seriam realizados em período contrário ao horário das aulas, pois a maioria possuía jornada dupla ou tripla de trabalho. Com a autorização da direção da escola para a realização do Grupo Focal durante o período em que todos se encontravam na escola, seis professores aceitaram colaborar com a pesquisa, após receberem informações detalhadas sobre a mesma. Assinaram o Termo de Consentimento Livre e Esclarecido (TCLE) e autorizaram a gravação dos três encontros, os quais tiveram duração média de uma hora e quarenta minutos cada (tempo referente ao período de duas aulas). Para tanto, foi utilizada uma sala devidamente preparada, com vistas a resguardar o sigilo das informações fornecidas pelos participantes. Enquanto os professores participavam do grupo, estagiários de Psicologia ficaram com as turmas, desenvolvendo atividades direcionadas ao esclarecimento, conscientização e prevenção do bullying. Para preservar a identidade dos participantes, seus nomes foram substituídos pelas siglas P1, P2, P3, P4, P5 e P6, correspondendo a um número aleatório atribuído a cada professor. Doravante nos referiremos aos professores por meio destas designações.

Os dados obtidos foram analisados segundo as proposições da análise de conteúdo (Bardin, 2010), que constitui um conjunto de técnicas que sintetizam e descrevem sistematicamente o conteúdo de comunicações com o objetivo de identificar núcleos de sentido que possibilitem a realização de inferências acerca dos seus significados. Empreendeuse neste trabalho a modalidade temática, a qual foi operacionalizada por meio de uma pré-análise das transcrições dos três encontros mediante leitura flutuante; codificação do material em recortes de sentido, também denominados unidades de registro (menor recorte de ordem semântica que se extrai do texto, podendo ser palavra-chave, tema, etc); quantificação e agrupamento das unidades de registro por semelhanças.

\section{RESULTADOS E DISCUSSÃO}

A identificação e intervenção no bullying pelos professores em sala de aula passam necessariamente pelo seu reconhecimento, o que implica a necessidade de domínio de seu significado (conceito) e de suas principais características (Allen, 2010). Os professores pesquisados compreendem-no enquanto "constrangimento a nível emocional, a nível físico e até mesmo espiritual" (P4), "quando um grupo xinga, cai em cima" (P2), "constrangimento, violência, agressão" (P5), "bulinar, mexer, hostilizar, ridicularizar" (P1), "humilhação" (P3). Como se pode notar, as definições fornecidas são gerais e incompletas, remetendo, na verdade, a fragmentos do conceito. Não apresentam sistematização, sequência, articulação ou profundidade, denotando ausência de um maior domínio teórico acerca do tema.

No que tange ao reconhecimento das formas de manifestação mais comuns deste fenômeno, os professores lograram identificá-las em seus aspectos direto e indireto, o que incluiu o reconhecimento de agressões de natureza física, verbal e psicológica, tais como, por exemplo: "chute, pancada" (P6), "brigas" (P1), "apelidos" (P2 e P4), "criticas" (P3), "deboche" (P5), "comentários, isolar o colega" (P4). Também fizeram referência acerca do desequilíbrio de poder existente entre vítimas e agressores no contexto de intimidação, "eles nunca praticam com alguém que 
tem a mesma força que eles" (P1). Não obstante, o caráter intencional e o aspecto de repetitividade das agressões não chegaram a ser citados. Tais aspectos são relevantes por circunscreverem as agressões enquanto ações intencionais, deliberadas, evitando, deste modo, que sejam percebidas por um viés normativo, como comportamentos característicos da idade. A repetitividade também é um ponto fundamental, uma vez que a recorrência das agressões impacta de modo mais grave o desenvolvimento dos sujeitos, bem como a qualidade de suas experiências na escolarização.

De modo geral, malgrado as dificuldades encontradas pelos professores na conceituação do fenômeno, eles mostraram conhecer parcialmente suas principais características e formas de manifestação, o que é fundamental para a identificação e intervenção nas situações ocorridas em sala de aula.

Cumpre, todavia, ressaltar que por volta dos 11 anos, idade média coincidente com o $6^{\mathrm{O}}$ ano escolar, as crianças tendem a apresentar ganhos em termos de sofisticação das estratégias agressivas, no sentido dessas se tornarem mais verbais e indiretas, porém não menos intensas ou prejudiciais, o que incrementa a dificuldade para a identificação do problema em sala de aula (Hernandez et al., 2012). Nota-se igualmente que, à medida que vão se tornando mais velhos, alguns agressores conseguem manipular intencionalmente e com maior êxito o modo como agem e se posicionam perante colegas e professores, mascarando a violência de modo a amenizá-la na percepção daqueles que a presenciam, dificultando assim o seu reconhecimento (Caravita, Di Blasio, \& Salmivalli, 2009).

A esse respeito, no grupo de professores, obteve-se referência a apenas uma situação referente ao bullying indireto (pressão emocional, exclusão de colega, ameaças, indiferença), apesar deste tipo de agressão constituir uma tônica a partir do $6^{\circ}$ ano (Allen, 2010; Fung, 2012). Os ataques físicos e verbais, mais visíveis, parecem ser mais valorizados, por serem mais facilmente identificáveis, embora, a partir do ano investigado, eles representem a menor parcela da intimidação praticada pelos alunos.

Ademais, evidenciou-se nos relatos dos participantes a ausência de menção à gravidade das ações que são praticadas pelos alunos e por eles observadas, tendo em vista que demonstraram possuírem crenças normativas em relação às agressões, interpretando-as, na maioria das vezes, como "brincadeiras" ou comportamentos típicos da idade (Silva et al., 2013), referindo que na sala de aula: "tudo é motivo para os alunos cutucarem uns aos outros, fazerem comentários" (P4); "faz mais no sentido de uma brincadeira" (P3); "ele reproduz o que vive" (P5); "é um aluno que está na fase da puberdade, não é um aluno que tem noção" (P3); "muitas das brincadeiras que os alunos têm, eles mesmos resolvem" (P2).

Conforme anteriormente mencionado, as crenças dos professores influenciam o seu comportamento diante do bullying e, por extensão, o comportamento dos alunos, de modo a afetar as ações de agressores, vítimas e espectadores (Hektner \& Swenson, 2012). Assim, a naturalização das agressões na sala de aula é danosa por desconsiderar a dinâmica da violência escolar enquanto um processo constituído por múltiplos aspectos que provocam consequências negativas tanto nos sujeitos nela diretamente envolvidos, quanto no contexto mais amplo da escola, família e comunidade em geral.

Portanto, o modo como os professores definem e percebem as situações presentes na sala de aula não pode ser admitido enquanto uma questão trivial, dependente de atributos pessoais, uma vez que, aqueles que possuem melhor domínio acerca das situações que configuram o bullying são menos propensos a desenvolverem crenças normativas em relação às suas práticas e mais predispostos a intervirem de forma mais intensiva diante dos eventos presenciados (Leff, Kupersmidt, Power, \& Patterson, 1999). Não obstante, se as crenças normativas tendem a implicar níveis mais baixos de percepção e, consequentemente, de intervenção, mesmo diante de episódios de agressão mais notórios (como ataques físicos), tais crenças, indiretamente, podem transmitir aos alunos a mensagem de que a intimidação é tolerada ou mesmo permitida. $\mathrm{O}$ resultado pode ser o de desestimular as vítimas a buscarem ajuda, seja por considerarem os professores como indiferentes ao seu sofrimento ou ainda por julgá-los incapazes de protegê-las das agressões, gerando um aumento sequencial na quantidade de ataques, prolongando o estado de intimidação das vítimas (Yoon \& Kerber, 2003). Assim, as crenças dos professores, interferindo nos comportamentos de todos os envolvidos, podem agenciar novos contornos para as atitudes de agressores, vítimas e espectadores, inibindo ou estimulando o bullying.

Cumpre destacar que, para o grupo investigado, existem determinados comportamentos de alunos cuja manifestação não é admitida, independentemente da forma como ocorram. São aqueles comportamentos que, de alguma forma, também geram mal-estar, incômodo aos professores, concorrendo para que se identifiquem com as vítimas. Como exemplo, citamse os comentários de dois participantes: "uma coisa que incomoda muito na sala de aula com a questão do bullying é quando eu escuto comentários dos colegas quanto à cor do outro [...] eu paro tudo o 
que eu tiver para fazer" (P5). "Eu percebo mais assim na área da sexualidade, principalmente se o menino não quer jogar bola, ele ainda nem decidiu o que quer ser e os meninos já decidiram por ele: gay, ô gayzinho, ô veadinho" (P1). Como se pode notar, existem elementos peculiares que interferem no modo como professores percebem e atuam perante o bullying, denotando a existência de uma parcialidade norteada por aspectos atitudinais frente a uma ou outra situação específica. Nestes exemplos, as atitudes frente à discriminação racial e à homossexualidade preponderam sobre os conhecimentos, no sentido de orientar a percepção e a reação diante das situações de bullying, independentemente de outras características dos alunos envolvidos nas agressões, do contexto e da gravidade da situação, etc.

No tocante ao modo como os participantes percebem sua própria atuação perante as agressões em sala de aula, um deles relatou que "o bullying é um cristal de várias partes [...]. E a solução para se lidar com ele é outro cristal, com outras partes e, muitas vezes, a gente fica com atitude repetitiva" (P4), querendo dizer que, no cotidiano das aulas, as situações de violência são por eles consideradas, muitas vezes, a partir de uma perspectiva única e isolada do contexto. Em complementação, os demais participantes deram a entender que geralmente o foco da intervenção se direciona exclusivamente ao comportamento manifesto. Assim, uma análise mais abrangente do acontecido não é realizada e os alunos são repreendidos ou punidos sempre da mesma maneira, sem maiores considerações. Como justificativa um deles avaliou que "na hora da situação, o envolvimento emocional, a situação em si, não deixa [...] pensar algo, ai [...] faz o que dá, repete sempre porque está mais fácil ali na hora" (P2).

É preciso sublinhar que, de modo geral, os professores manifestaram não se sentirem adequadamente preparados para lidarem com o bullying. Enunciaram o desejo de que lhes fosse oferecida formação específica acerca do tema, bem como que houvesse uma equipe multidisciplinar na escola que lhes oferecesse suporte, uma vez que, diante das dificuldades que enfrentam na gestão de conflitos entre os alunos, muitas vezes, eles não vislumbram saídas adequadas. A esse respeito, um participante mencionou: "já cometi a doideira de começar a chamar todo mundo, sabe, aqueles que estavam praticando, façam uma roda aí, ai eu comecei a arrumar apelidos para eles". De acordo com Ahtola et al. (2012), quando os professores sentem que possuem as competências necessárias para lidarem eficazmente com este fenômeno, apresentam maior confiança, motivação e interesse para identificar e intervir nas situações presentes no cotidiano das aulas.

Referiram ainda que frente às dificuldades para um manejo adequado, eles mesmos cometem violência: "a gente desce na hora do recreio. É porque fulano... qual? Aquele que está querendo ser veadinho. Aquela rotulação, olha como a gente sempre pega pelo lado negativo: aquele que apareceu com aquela bolinha de crack [...], a gente rotula" (P3). Justificam os ataques que também praticam em relação aos alunos como representando uma defesa contra determinadas agressões que presenciam, direcionadas a outros alunos e/ou a eles mesmos, indicando assim a existência de momentos nos quais também se sentem vítimas de violência, muito pressionados ou acuados, não conseguindo visualizar alternativa a não ser a emissão de comportamentos igualmente intimidatórios.

É fato que, na intenção de se manter a disciplina, muitas vezes, uma posição mais rígida do professor se faz necessária para a retomada do controle disciplinar (Silva \& Nogueira, 2008). Contudo, no grupo investigado, essa postura mais severa se confunde com agressões, humilhações e rotulagem dos alunos. Além disso, nas intervenções realizadas pesam ainda outros fatores, tais como, por exemplo, a disponibilidade dos professores no momento em que presenciam a agressão, referente ao andamento do conteúdo programático e estado de humor: "quando eu identifico, depende do dia, da hora, do meu humor, da minha criatividade" (P4); "percebo que depende do nosso humor, depende do dia, depende também do conteúdo" (P5); "nós temos um conteúdo que é cobrado em avaliação [...] nem toda aula que acontece, você tem aquele tempo para parar realmente" $(\mathrm{P} 3)$.

Há também quem indique que intervir ou não no bullying depende das características dos alunos envolvidos, sobretudo do histórico disciplinar, conforme sugere o relato: "quando é com aquela panela, tudo da mesma estirpe, eu deixo para lá, não sei, eu posso estar errada" (P1). O participante, neste trecho, equipara os alunos envolvidos nas agressões, o que, a rigor, levaria ao questionamento se as situações a que se refere poderiam ou não ser classificadas efetivamente como bullying, na medida em que ele obrigatoriamente implica a existência de um desequilíbrio de poder entre vítima(s) e agressor(es). De todo modo, fica claro que os professores, ao levarem em conta o histórico disciplinar dos alunos, são discricionários quanto a intervir ou não em situações em sala de aula, o que pode ocasionar equívocos, tendo em vista que nem todos os alunos que causam problemas de natureza disciplinar possuem condições similares de ataque e/ou proteção em relação ao bullying. 
Concernente às formas de intervenção propriamente ditas, segundo os relatos obtidos, essas ocorreriam mediante a transferência de responsabilidade do professor ao aluno, no tocante à busca do conhecimento acerca da problemática: "mando eles pesquisarem sobre bullying, peço para eles irem lá na frente dar uma aula [...]" (P4); também pela descrição de situações ocorridas previamente, em outros contextos: "falo com eles sobre as situações que aconteceram nos países desenvolvidos, nos Estados Unidos, daqueles meninos que saíram atirando na escola inteira" (P1); por meio do estímulo à reflexão sobre a situação ocorrida: "outras vezes eu paro e faço uma reflexão" (P4); "eu puxo para o lado da reflexão também" (P3); "começo a refletir sobre o que está acontecendo" (P5); expurgando o incômodo (ou aquele que é identificado como o agressor): "falei para ele ir para fora" (P2); ou transferindo a responsabilidade pela intervenção a outras figuras de autoridade: "geralmente a gente encaminha para a supervisão, diretoria, chama a família" (P6).

É importante notar que os relatos sobre intervenção referem-se a situações, em sua maioria, em que as agressões estão em curso, denotando-se pouco ou nenhum investimento de caráter eminentemente preventivo, pois não se obteve referência à prevenção enquanto medida mais eficiente em determinadas circunstâncias. A literatura reitera que intervenções eficazes necessitam considerar o ambiente escolar em seus vários níveis de organização, a participação da família e a ênfase em medidas preventivas (Ahtola et al., 2012; Boulton et al., 2012; Dake et al., 2003; Janosz et al., 2008; Wendt et al., 2010).

Nesse sentido, o Programa Norueguês de Prevenção ao Bullying se projeta como um dos programas direcionados à prevenção que proporcionam melhores resultados, uma vez que diversas avaliações constataram que ele reduz as práticas de intimidação nas escolas em até $50 \%$. Dentre seus principais componentes têm-se ações de conscientização e de inserção das famílias no combate à violência, criação de regras contra o bullying em sala de aula, reflexões regulares sobre o tema com os alunos, criação de um comitê escolar de prevenção à violência e aumento de supervisão de adultos no recreio, na entrada, na saída e nos intervalos entre as aulas (Dake et al., 2003).

Em contraste a esse modelo, pode-se afirmar que os métodos empregados pelos professores pesquisados parecem remeter a ações fragmentadas, geralmente reativas aos eventos identificados como bullying e circunscritas ao contexto estrito das agressões ou da sala de aula. Outras vezes os alunos envolvidos são encaminhados à direção escolar ou convoca-se a família para a abordagem do problema. Evidências sugerem que abordagens fragmentadas ou realizadas com recursos inadequados exercem pouco impacto sobre o bullying (Yoon \& Kerber, 2003). Em se tratando especificamente da sala de aula, espaço em que o professor está em melhores condições para identificar e intervir nas situações de violência, ele pode oportunizar um ambiente que desencoraje qualquer tipo de comportamento agressivo, mediante a criação de regras claras, realização de supervisão efetiva, intervenções preventivas e "curativas", bem como através do envolvimento dos alunos na discussão e no combate à violência. É importante não perder de vista, entretanto, que intervenções mais contundentes e eficazes, conforme tem-se demonstrado, implicam a atuação em conjunto de escola, família, professores e alunos.

\section{CONSIDERAÇÕES FINAIS}

Como principais resultados do estudo implementado destaca-se o fato de os professores pesquisados possuírem, com relação ao bullying, um conhecimento que lhes permite definir e caracterizar o problema, porém de um modo que deixa escapar elementos no sentido de disporem de uma conceituação completa e aprofundada. Eles referiram não se sentirem adequadamente preparados para identificarem e para lidarem com as práticas de bullying na sala de aula. Ademais, identificou-se que possuiriam crenças normativas acerca de algumas de suas situações e estariam mais propensos a intervirem nos casos que envolvam agressões mais facilmente notáveis ou que atrapalhem o andamento das aulas. Identificou-se ainda que variáveis pessoais (estado de humor), escolares (cobranças com relação ao desenvolvimento do conteúdo programático) e relativas aos alunos (histórico disciplinar) parecem interferir nas intervenções que realizam frente às agressões que presenciam. Tais intervenções compreendem atitudes cujo alcance geralmente se restringe à situação em si e ao contexto da classe. A inserção da direção escolar e das famílias dos alunos é rara, bem como as medidas voltadas à prevenção.

Depreende-se que os dados obtidos, malgrado raras distinções, se assemelham àqueles obtidos por outras investigações (Troop-Gordon \& Ladd, 2013; Yoon \& Kerber, 2003) realizadas em uma realidade sociocultural diferente, o que demonstra a relevância do papel desempenhado pelo professor tanto na prevenção quanto na gestão da problemática na sala de aula. Assim sendo, a formação deles constitui um aspecto a ser trabalhado em programas direcionados ao bullying escolar, pois uma maior competência dos professores pode contribuir para o reconhecimento da gravidade inerente a todas as formas de agressão praticadas 
pelos alunos, colaborar para a modificação de crenças normativas e estimular intervenções mais adequadas, especialmente se voltadas à prevenção (Fung, 2012).

No que tange às limitações apresentadas pela presente pesquisa, compete mencionar aquelas relacionadas à sua operacionalização (não se logrou a participação da totalidade dos professores da série pesquisada) e ao delineamento metodológico, em função do qual concentrou-se esforços em uma única escola, sendo essa pública, envolvendo um número reduzido de professores. Nesse sentido, também é necessário considerar que alguns dos participantes podem ter fornecido informações tendenciosas na intenção de não se exporem negativamente perante os demais membros do grupo, fornecendo respostas que consideravam socialmente esperadas. Ademais, o tempo existente entre os encontros do grupo focal, embora faça parte de sua metodologia, pode ter possibilitado aos participantes a oportunidade para pesquisarem sobre o tema e/ou alterarem seus posicionamentos. Estudos futuros, com objetivos semelhantes, podem procurar conhecer o pensamento e o comportamento de professores inseridos em realidades educacionais mais diversificadas, empregando-se, talvez, metodologia observacional, com abordagem quali-quantitativa, com vistas a obter resultados que possam efetivamente subsidiar políticas públicas na área.

De todo modo, apesar das limitações, observa-se que a investigação oportunizou a obtenção de dados mais aprofundados e contextualizados, uma vez que se pautou no estudo idiossincrático dos participantes, privilegiando seus modos de produção de significados e sentidos acerca da situação investigada, característica que potencializa e valida estudos qualitativos relacionados à investigação de contextos e realidades sociais. Para finalizar, considerando-se a importância da atuação do professor diante do bullying, sugere-se que os resultados obtidos constituam ponto de partida para posteriores estudos. Outras investigações podem, por exemplo, pesquisar se diferenças no nível de conhecimento dos professores com relação ao bullying concorre para que possuam maior capacidade de identificação e manejo do problema, em sala de aula, e se isso também tem reflexo sobre as atitudes e principalmente sobre as crenças envolvendo o fenômeno.

\section{REFERÊNCIAS}

Ahtola, A., Haataja, A., Kärnä, A., Poskiparta, E., \& Salmivalli, C. (2012). For children only? Effects of the KiVa antibullying program on teachers. Teaching and Teacher Education, 28(6), 851-859. doi: http://dx.doi.org/10.1016/j.tate.2012.03.006

Allen, K. P. (2010). Classroom management, bullying, and teacher practices. The Professional Educator, 34(1), 01-16.
Antoni, C., Martins, C., Ferronato, M. A., Simões, A., Maurente, V., Costa, F., \& Koller, S. H. (2001). Grupo focal: método qualitativo de pesquisa com adolescentes em situação de risco. Arquivos Brasileiros de Psicologia, 53(2), 38-53.

Associação Brasileira Multiprofissional de Proteção à Criança e ao Adolescente - ABRAPIA. (2002). Programa de redução do comportamento agressivo entre estudantes. Disponível em: http://www.observatoriodainfancia.com.br/IMG/pdf/doc-154. pdf. Acesso em: 29 dez. 2009.

Bardin, L. (2010). Análise de conteúdo. Lisboa: Edições 70.

Boggio, F., \& Pavão, T. M. (2005). Pitoco de guache. In Pavão, T. M. Fudêncio e seus amigos [vídeo]. Brasil: Music Television. Acessado em: 26 de agosto de 2010. Disponivel em: http://www. youtube.com/watch? $\mathrm{v}=\mathrm{fLb60SZ1Epk}$

Boulton, M., Woodmansey, H., Williams, E., Spells, R., Nicholas, B., Laxton, E., Holman, G., \& Duke, E. (2012). Associations between peer bullying and classroom concentration: evidence for mediation by perceived personal safety and relationship with teacher. Educational Psychology, 32(3), 277-294. doi: 10.1080/01443410.2011.648903

Caravita, S. C. S., Di Blasio, P., \& Salmivalli, C. (2009). Unique and Interactive Effects of Empathy and Social Status on Involvement in Bullying. Social Development, 18(1), 140-163. doi: 10.1111/j.1467-9507.2008.00465.x

Carroll, A., Houghton, S., Wood, R., Unsworth, K., Hattie, J., Gordon, L., \& Bower, J. (2009). Self-efficacy and academic achievement in Australian high school students: the mediating effects of academic aspirations and delinquency. Journal of Adolescence, 32(4), 797-817. doi: 10.1016/j.adolescence.2008.10.009

Dake, J. A., Price, J. H., Telljohann, S. K., \& Funk, J. B. (2003). Teacher perceptions and practices regarding school bullying prevention. Journal of School Health, 73(9), 347-355.

Due, P., Holstein, B. E., Lynch, J., Diderichsen, F., Gabhain, S. N., Scheidt, P., \& Currie, C. (2005). Bullying and symptoms among school-aged children: International comparative cross sectional study in 28 countries. European Journal of Public Health, 15(1), 128-132. doi: 10.1093/eurpub/cki105

Fisher, R. M. (2010). Bullying escolar no Brasil: relatório final. São Paulo: CEATS/FIA. Disponível em: http://escoladafamilia. fde.sp.gov.br/v2/Arquivos/pesquisa-bullying escolar no brasil. pdf. Acessado em: 07 ago. 2011.

Fung, A. L. (2012). Intervention for aggressive victims of school bullying in Hong Kong: a longitudinal mixed-methods study. Scandinavian Journal of Psychology, 53(4), 360-367. doi: 10.1111/j.1467-9450.2012.00953.x

Hansen, T. B., Steenberg, L. M., Palic, S., \& Elklit, A. (2012). A review of psychological factors related to bullying victimization in schools. Aggression and Violent Behavior, 17(4), 383-387. doi: 10.1016/j.avb.2012.03.008

Hektner, J. M., \& Swenson, C. A. (2012). Links from teacher beliefs to peer victimization and bystander intervention tests of mediating processes. The Journal of Early Adolescence, 32(4), 516-536. doi: 10.1177/0272431611402502

Hernandez, D., Floden, L., \& Bosworth, K. (2010). How safe is a school? An exploratory study comparing measures and perceptions of safety. Journal of School Violence, 9(4), 357-374. doi: 10.1080/15388220.2010.508133

Janosz, M., Archambault, I., Pagani, L. S., Pascal, S., Morin, A. J. S., \& Bowen, F. (2008). Are there detrimental effects of witnessing school violence in early adolescence? Journal of Adolescent Health, 43(1), 600-608. doi: 10.1016/j.jadohealth.2008.04.011

Kumpulainen, K., Räsänen, E., Henttonen, I., Almqvist, F., Kresanov, K., Linna, S. L., Moilanen, I., Piha, J., Puura, K., \& Tamminen, T. (1998). Bullying and psychiatric symptoms among elementary school-age children. Child Abuse Neglect, 22(7), 705-717. 
Leff, S. S., Kupersmidt, J. B., Power, T. J., \& Patterson, C. J. (1999). Factors influencing teacher identification of peer bullies and victims. School Psychology Review, 28(3), 505-517.

Lisboa, C., Braga, L. L., \& Ebert, G. (2009). O fenômeno bullying ou vitimização entre pares na atualidade: definições, formas de manifestação e possibilidades de intervenção. Contextos Clínicos, 2, 59-71.

Magklara, K., Skapinakis, P., Gkatsa, T., Bellos, S., Araya, R., Stylianidis, S., \& Mavreas, V. (2012). Bullying behaviour in schools, socioeconomic position and psychiatric morbidity: a crosssectional study in late adolescents in Greece. Child and Adolescent Psychiatry and Mental Health, 6(8), 02-13.

Malta, D. C., Silva, M. A. I., Mello, F. C. M., Monteiro, R. A., Sardinha, L. M. V., Crespo, C., \& Porto, D. L. (2010). Bullying nas escolas brasileiras: resultados da Pesquisa Nacional de Saúde do Escolar (PeNSE), 2009. Ciência \& Saúde Coletiva, 15(Suppl. 2), 3065-3076. doi: 10.1590/S1413-81232010000800011

Minayo, M. C. S. (2010). O desafio do conhecimento: pesquisa qualitativa em saúde. São Paulo: Hucitec.

Olweus, D. (2013). School Bullying: Development and Some Important Challenges. Annual Review of Clinical Psychology, 9(1), 751-780. doi: 10.1146/annurev-clinpsy-050212-185516

O'Moore, M., \& Kirkham, C. (2001). Self-esteem and its relationship to bullying behavior. Aggressive Behavior, 27(1), 269-283. doi: 10.1002/ab.1010

Pingoelo, I., \& Horiguela, M. L. M. (2010). Bullying na sala de aula. De Jure: Revista Jurídica do Ministério Público do Estado de Minas Gerais, 15(2), 145-156.

Pires, J. (2011). A pesquisa e os jovens que dela participaram. In Minayo, M. C. S., Assis, S. G., \& Njaine, K. (Eds.). Amor $e$ violência: um paradoxo das relações de namoro e do 'ficar' entre jovens brasileiros (pp. 45-54). Rio de Janeiro: Fiocruz.

Powell, R. A., \& Single, H. M. (1996). Focus groups. International Journal of Quality in Health Care, 8(5), 499-504. doi: 10.1093/ intqhe/8.5.499

Rech, R. R., Halpern, R., Tedesco, A., \& Santos, D. F. (2013). Prevalence and characteristics of victims and perpetrators of bullying. Jornal De Pediatria, 89(2), 164-170. doi: 10.1016/ j.jped.2013.03.006

Roth, G., Kanat-Maymon, Y., \& Bibi. (2011). Prevention of school bullying: the important role of autonomy-supportive teaching and internalization of pro-social values. British Journal of Educational Psychology, 81(3), 654-666. doi: 10.1348/20448279.002003

Rothon, C., Head, J., Klineberg, E., \& Stansfeld, S. (2011). Can social support protect bullied adolescents from adverse outcomes? A prospective study on the effects of bullying on the educational achievement and mental health of adolescents at secondary schools in East London. Journal of Adolescence, 34(1), 579-588. doi: 10.1016/j.adolescence.2010.02.007
Salmivalli, C., \& Voeten, M. (2004). Connections between attitudes, group norms, and behaviour in bullying situations. International Journal of Behavioral Development, 28(3), 246258. doi: $10.1080 / 01650250344000488$

Sampson, R. (2009). Bullying in Schools. New York, NY: Center for Problem-Oriented Policing.

Silva, L. C., \& Nogueira, M. A. (2008). Indisciplina ou violência na escola: uma distinção possível e necessária. In Gonçalves, L. A. O., \& Tosta, S. P. (Eds.). A síndrome do medo contemporâneo e a violência na escola (pp. 15-62). Belo Horizonte, MG: Autêntica.

Silva, M. A., Pereira, B., Mendonca, D., Nunes, B., \& Oliveira, W. A. (2013). The involvement of girls and boys with bullying: an analysis of gender differences. Int J Environ Res Public Health, 10(12), 6820-6831. doi: 10.3390/ijerph10126820

Smith, P. K., Smith, C., Osborn, R., \& Samara, M. (2008). A content analysis of school anti-bullying policies: progress and limitations. Educational Psychology in Practice, 24(1), 1-12. doi: 10.1080/02667360701661165

Thornberg, R., Thornberg, U. B., Alamaa, R., \& Daud, N. (2014). Children's conceptions of bullying and repeated conventional transgressions: moral, conventional, structuring and personalchoice reasoning. Educational Psychology, 1-17. doi: 10.1080/ 01443410.2014.915929

Wendt, G. W., Campos, D. M. d., \& Lisboa, C. S. M. (2010). Agressão entre pares e vitimização no contexto escolar: bullying, cyberbullying e os desafios para a educação contemporânea. Cadernos de Psicopedagogia, 8, 41-52.

Yoon, J. S., \& Kerber, K. (2003). Bullying: elementary teachers' attitudes and intervention strategies. Research in Education, 69(1), 27-36.

Zaine, I., Reis, M. J. D., \& Pandovani, R. C. (2010). Comportamentos de bullying e conflito com a lei. Estudos de Psicologia, 27(3), 375-382. doi: 10.1590/S0103-166X2010000300009

\section{Autores:}

Jorge Luiz da Silva - Doutorando pelo Programa Enfermagem em Saúde Pública, Universidade de São Paulo, Ribeirão Preto, SP, Brasil.

Wanderlei Abadio de Oliveira - Doutorando pelo Programa Enfermagem em Saúde Pública, Universidade de São Paulo, Ribeirão Preto, SP, Brasil.

Marina Rezende Bazon - Doutora em Psicologia, Universidade de São Paulo, Ribeirão Preto, SP, Brasil.

Sálua Cecílio - Doutora em Sociologia, Universidade de Uberaba, Uberaba, MG, Brasil.

\section{Endereço para correspondência:}

Jorge Luiz da Silva

Rua Monte Alegre, 150, Bloco 4, Apto 404 - Monte Alegre

CEP 14051-260 Ribeirão Preto, SP, Brasil

E-mail: jorgelsilva@usp.br

Recebido em: 02.04.2013

Aceito em: 21.03.2014 